\title{
Nuclear Energy Loss and Range of Heavy Ions in SiO2, LiF and Kapton Polyatomic Targets: A Monte Carlo study
}

\author{
J. El Asri ${ }^{1}$, O. El Bounagui ${ }^{2, *}$, N. Tahiri ${ }^{3}$, H. Erramli ${ }^{4}$ and A. Chetaine ${ }^{1}$ \\ ${ }^{I}$ Nuclear Reactor, Nuclear Security and Environment Group Energy Centre. Faculty of Sciences, Mohammed V University in Rabat, Morocco. \\ ${ }^{2}$ EPHE-SM, Faculty of Sciences, Mohammed V University in Rabat, Morocco. \\ ${ }^{3}$ LaMCScI, Faculty of Sciences, Mohammed V University in Rabat, Morocco. \\ ${ }^{4}$ Faculty of Sciences Semlalia, University Cadi Ayyad, Marrakech, Morocco.
}

\begin{abstract}
This paper is dedicated to study the nuclear energy loss in amorphous targets $\mathrm{SiO}_{2}, \mathrm{LiF}$ and Kapton for different charged incident particles at energy $\mathrm{E}>0.01 \mathrm{keV}$, by using Monte Carlo simulations. The nuclear stopping power and mean range are investigated. However, the nuclear stopping power and its maximum increases with increasing the atomic number of charged particles. All results are compared with existing SRIM data, PSTAR and ASTAR values. Finally, using the MonteCarlo simulation, a determination was also made of mean range of ions in amorphous targets at energies from 10 to $400 \mathrm{keV}$. Our results were compared with experimental data.
\end{abstract}

Keywords: Nuclear energy loss; Amorphous targets; Monte Carlo simulations; Charged particles; Mean range of ions.

\section{INTRODUCTION}

The energy loss of ions in amorphous targets has mainly been investigated mainly in the low, intermediate and high ion energy [1-5]. The binary collision approximation has long been used in slowing down simulations of the interactions of charged particles with target materials, as well as being the basis of large analytical theory in this area [6-8]. There is a long-standing of interest in stopping powers for heavy charged particles in matter, because such information is needed in many areas of basic and applied physics such as: Radiological physics and biomedical dosimetry [9]. Today proton and helium penetration of matter are already well known experimentally and are inventoried in the SRIM data and PSTAR/ASTAR programs [10,11]. The Monte Carlo simulation has many numbers of advantages over present analytical formulation based on transport theory. It allows more rigorous treatment of elastic scattering, explicit consideration of energy of surfaces and interfaces. By using this method it's easy determination of energy and angular distributions [12].

The Monte Carlo simulation thus takes into account a wide range of possibilities and helps us reduce uncertainty. This calculation method is very flexible; it allows us to vary risk assumptions under all parameters and thus model a range of possible outcomes.

\section{NUCLEAR STOPPING POWER}

The interactions of an ion with the matter gather a whole of the following process which an incident particle yields its energy to target. The kinetic energy communicated to these materials produces modifications of the target atom. It is thus the transferred energy which is responsible for the defects created. The transfers of the energy are divided on two parts: (i) the inelastic collisions constitute the principal mode of energy loss; it acted of exchange of loads between the projectile and target atoms, of an ionization of the target atoms or excitation of the electrons [13-16] and (ii) the elastic collisions result primarily by displacements of the target atoms and thus in crystalline defects in the structure [7]. The stopping power of heavy charged particles at low energy using the semi-thick target method is described in detail in the literature [17].

The nuclear energy losses may be associated with significant angular deflection dependent on ion and target mass whereas electronic processes exert a rather minor influence on the scattering angle. This mode of energy loss occurs mainly at low energy (figure 1). There are very few experimental results quantifying these energy losses; loss of nuclear energy is therefore often evaluated theoretically. The Coulombian diffusion cross section of the charged particles by the nuclei of the medium is calculated, as well as the energy transfer during this process.

The energy loss of particles in matter is of considerable interest in several different branches of physics. Ion implantation is a widely used technique in for instance semiconductor fabrication and different branches of materials science.

At very high energies (larger than several hundred $\mathrm{MeV}$ ), the slowing down of all charged particles is contributed to by bremsstrahlung, Cherenkov radiation and nuclear reactions.

At lower energies, the slowing down of ions is traditionally separated into two distinct processes: electronic and nuclear

\footnotetext{
* Corresponding Auther : elbounagui@gmail.com
} 
slowing down or stopping power. The sum of these two processes is called the total stopping power

$$
S(E)=S_{e}(E)+S_{n}(E)
$$

With nuclear stopping one means elastic collisions between the ion and atoms in the sample. If one knows the form of the repulsive potential $\mathrm{V}(\mathrm{r})$ between two atoms, it is possible to calculate the nuclear stopping power $S_{n}(E)$. Nowadays, the repulsive potential between two atoms can be obtained to great accuracy from quantum mechanical calculations.

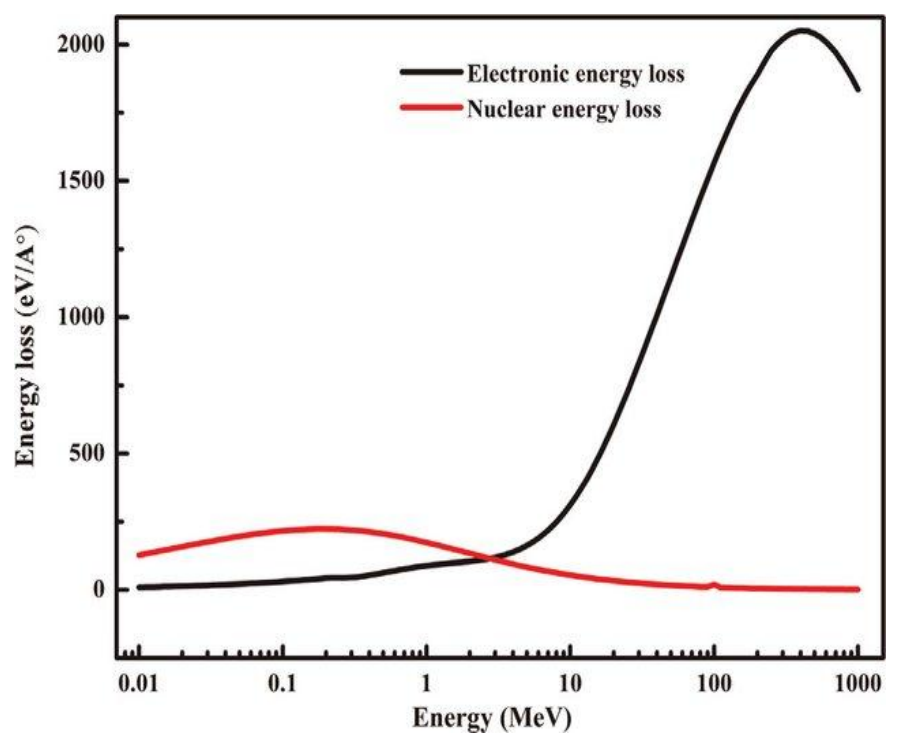

Figure 1: Ratio between nuclear and electronic stopping power [18]

The interaction treatment requires taking into account the effective charge of the incident ion and an appropriate form of potential taking into account the shielding effect due to the electrons of the nucleus. The potential is described in the following form:

$$
V(r)=\frac{z Z e^{2}}{r} \phi\left(\frac{r}{a}\right)
$$

Where the first factor corresponds to the coulombian potential with a charge ze for the projectile and Ze for the nucleus making up the medium being traversed. The $\phi$ factor represents the screen term and a, the screening length due to electrons. Common expressions of the screen parameter are:

$$
a=\frac{0,8853 a_{0}}{\left(z^{2 / 3}+Z^{2 / 3}\right)^{1 / 2}}
$$

or :

$$
a=\frac{0,8853 a_{0}}{\left(z^{1 / 2}+Z^{1 / 2}\right)^{3 / 2}}
$$

with $\mathrm{a}_{0}$ the Bohr radius $\left(\mathrm{a}_{0}=0.528 \AA\right.$ ). These formulae take into account the interpenetration electronic clouds of the incident particle and nucleus. A high energy, the calculation of energy loss by nuclear collision neglects the screen effect due to electrons $[12,19]$.

The energy transfer $\mathrm{T}$ to the target atom in a single collision is given by

$$
T=\frac{4 M_{1} M_{2}}{\left(M_{1}+M_{2}\right)^{2}} E \sin ^{2}\left(\frac{\theta}{2}\right)=\gamma E \sin ^{2}\left(\frac{\theta}{2}\right)
$$

Where $\mathrm{M}_{1}$ and $\mathrm{M}_{2}$ are the atomic masses of the particle and the target respectively, $\mathrm{E}$ is the incident energy.

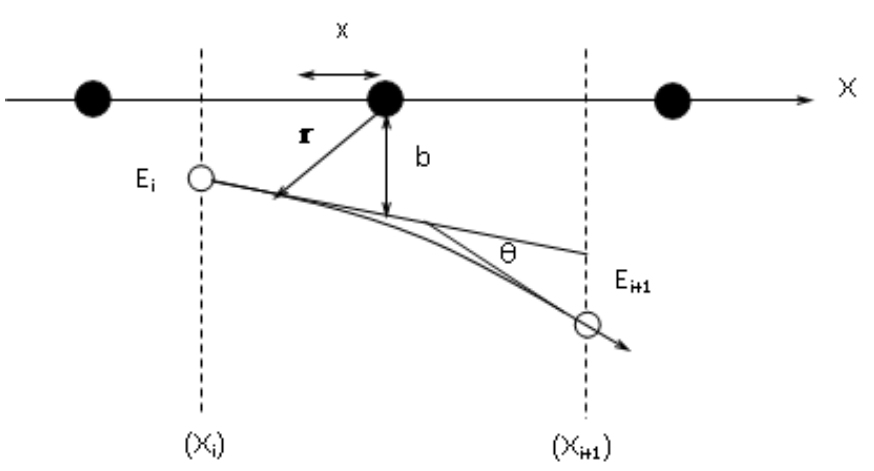

Figure 2: Schematic collision between ions and target

The nuclear stopping power is related to the kinetic-energy transfer from the incoming ion to the target atoms [21]. Then the mean energy-loss per unit path due to elastic collisions is:

$$
\left(-\frac{d E}{d x}\right)_{n}=N \int_{0}^{\infty} T(b) d \sigma=N S_{n}(E)
$$

Where $\mathrm{N}$ is the atomic density of the target, $\mathrm{S}_{\mathrm{n}}$ is the nuclear stopping cross-section, $\mathrm{b}$ is the impact parameter and $\sigma$ is the scattering cross section.

For heavy ions, the nuclear stopping power is predominant and the mean range can be simply obtained by the integration of the nuclear stopping power as:

$$
R(E)=\int_{0}^{E} \frac{d E^{\prime}}{N S_{n}\left(E^{\prime}\right)}
$$

\subsection{Calculation method}

Each incident ion is characterized by its atomic number, its atomic mass, its energy, its direction, and its space position. Using Monte-Carlo simulation, we can thus follow the evolution of these parameters. The particle is assumed to change direction as a result of binary collisions and to move in a straight path between two consecutive collisions. The energy of the particle is reduced as a result of elastic collision. The target is considered amorphous with atoms at random locations 
and the directional properties applicable for a crystalline material are ignored [7].

The calculation of the nuclear energy loss has been performed by considering elastic collisions:

$$
<T>=\int T(b) d \sigma
$$

The collision impact parameter $\mathrm{b}$ is determined by random numbers which are evenly distributed between 0 and 1 , and then the scattering angle $\theta$ in the center of mass system is calculated from the formalism for nuclear scattering based on the Moliere potential [20]

To determine the distance $\mathrm{dl}$ between collisions, equations (7) is used:

$$
d l=-\frac{1}{N \sigma} \ln (\xi)
$$

$\xi$ is the random number uniformly distributed between 0 and 1 .

The mean range $\mathrm{R}$ is obtained by using this expression:

$$
R=\int<\cos \theta>d l
$$

Each path length element $\mathrm{dl}$ of the ion incident trajectory is projected on the $\mathrm{x}$ axis by multiplying with the corresponding directional cosine.

The emission angle $\theta$ is generated according to the selected angular distribution using the Von Neumann mathematical method [22, 23]. The initial direction is specified by the directional cosines using the beam trajectory as the $\mathrm{x}$-axis:

$$
\theta=\cos ^{-1}\left(1-2 \xi^{\prime}\right)
$$

where $\xi^{\prime}$ is a random number.

The azimuthal scattering angle $\phi$ is randomly sampled in the range $[0,2 \pi]$, selected using the relation:

$$
\phi=2 \pi \xi^{\prime \prime}
$$

$\xi^{\prime \prime}$ is a random number uniformly distributed between 0 and 1 ; The maximum energy transfer, $\mathrm{T}_{\max }$, is given by :

$$
T_{\max }=\gamma E
$$

And the minimum energy transfer $\mathrm{T}_{\min }$ is :

$$
T_{\min }=\gamma E \sin ^{2}\left(\frac{\theta_{\min }}{2}\right)
$$

where $\theta_{\min }$ is the minimum scattering angle (in this program, usually $\theta_{\min }$ in the laboratory system is 1 degree).

The calculations are treated by the application of computer simulation technique. The random number is given by using a subroutine to generate the number $\xi$. The program simulates the trajectories of the incidental particle in the matter, with the assistance of the random procedure. Knowing the energy, initial direction and to follow the evolution of these parameters when the ion crosses the matter by using the Monte Carlo simulation. The particle defined by its only angle, the generation of the direction carried out by an equiprobable pulling on the angular interval $[0, \pi]$.

\subsection{Choice of Materials}

We have used, for this theoretical calculations of nuclear stopping powers, different amorphous targets such $\mathrm{SiO}_{2}, \mathrm{LiF}$ and Kapton. The average atomic number and the average atomic weight based on current values of constituent of amorphous targets are presented in table 1 .

Table 1. Average atomic number $(\bar{Z})$ and average atomic weight $(\overline{\mathrm{A}})$ of Silicon dioxide, Lithium fluoride and Kapton polyimide film

\begin{tabular}{lcc}
\hline Target & $\overline{\mathrm{Z}}$ & $\overline{\mathrm{A}}$ \\
\hline Silicon dioxide $\left(\mathrm{SiO}_{2}\right) \rho=2.210 \mathrm{~g} / \mathrm{cm}^{3}$ & 9.99 & 19.99 \\
\hline $\begin{array}{l}\text { Lithium fluoride }(\mathrm{LiF}) \\
\rho=2.635 \mathrm{~g} / \mathrm{cm}^{3}\end{array}$ & 4.55 & 8.73 \\
\hline $\begin{array}{l}\text { Kapton polyimide film }\left(\mathrm{C}_{22} \mathrm{H}_{10} \mathrm{O}_{5} \mathrm{~N}_{2}\right) \\
\rho=1.420 \mathrm{~g} / \mathrm{cm}^{3}\end{array}$ & 5.03 & 9.80 \\
\hline
\end{tabular}

\section{RESULTS AND DISCUSSIONS}

The results of the calculation using the Monte Carlo simulation are shown in figures 3 and 4 . These figures show the variation of the nuclear energy loss as a function of the incident particle energy. This study was carried out for proton and helium in $\mathrm{SiO}_{2}, \mathrm{LiF}$ and Kapton at energies from $0.01 \mathrm{keV}$ to $10 \mathrm{MeV}$.

Our results were found to be in excellent agreement with those obtained by SRIM code [24] and PSTAR/ASTAR [25, 26]. On the other hand, the nuclear energy loss of incident proton is low, this is due to the fact that the incident particle is light, and the impact parameter is very important, compared with helium ion in $\mathrm{SiO}_{2}, \mathrm{LiF}$ and Kapton amorphous targets.

A common feature for all ions is that the nuclear stopping as a function of ion energy has a maximum at a relatively low energy, and that the nuclear stopping of the ion decreases as the energy of the ion increases. This means that the nuclear stopping is important only for low ion velocities. 
(a)

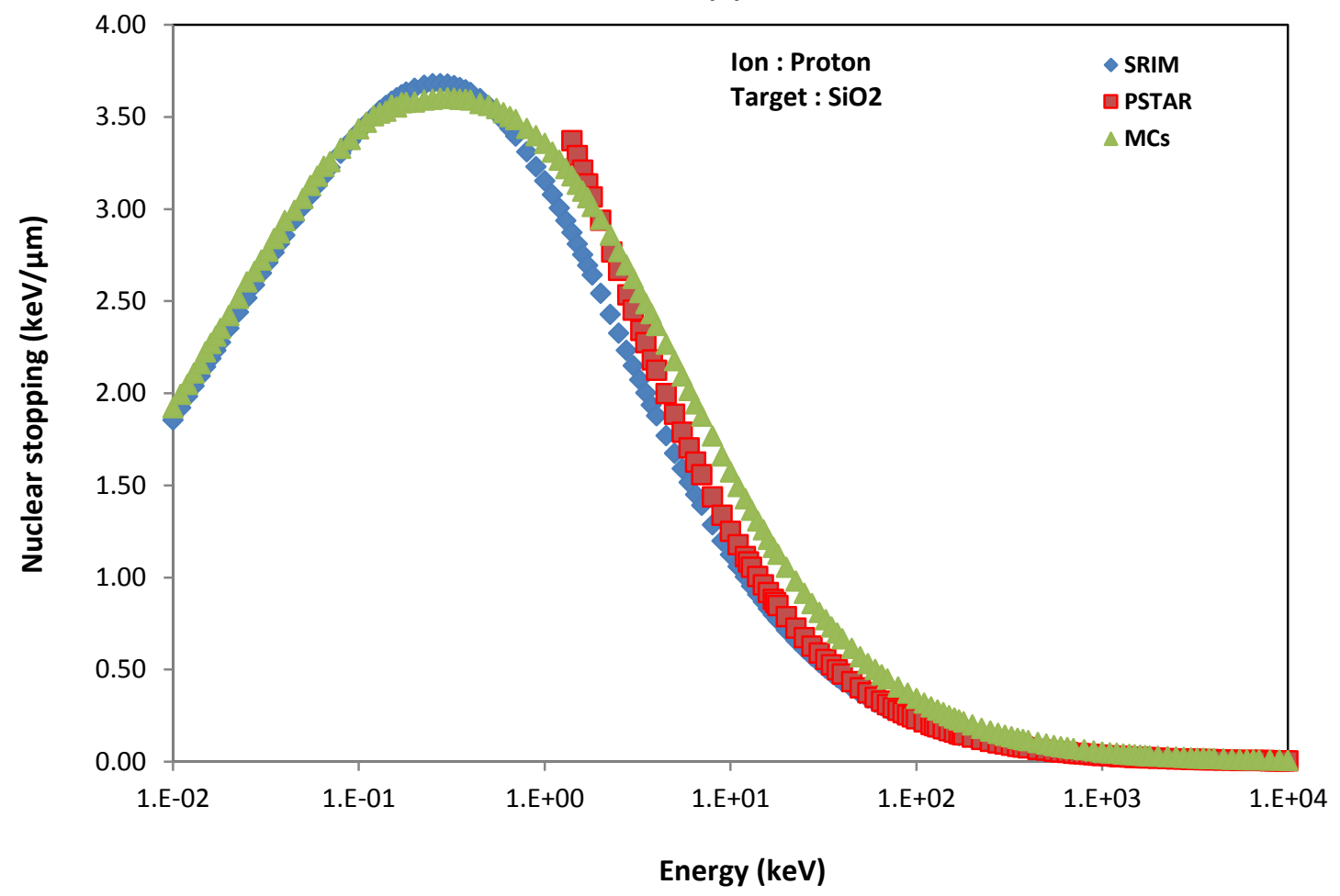

(b)

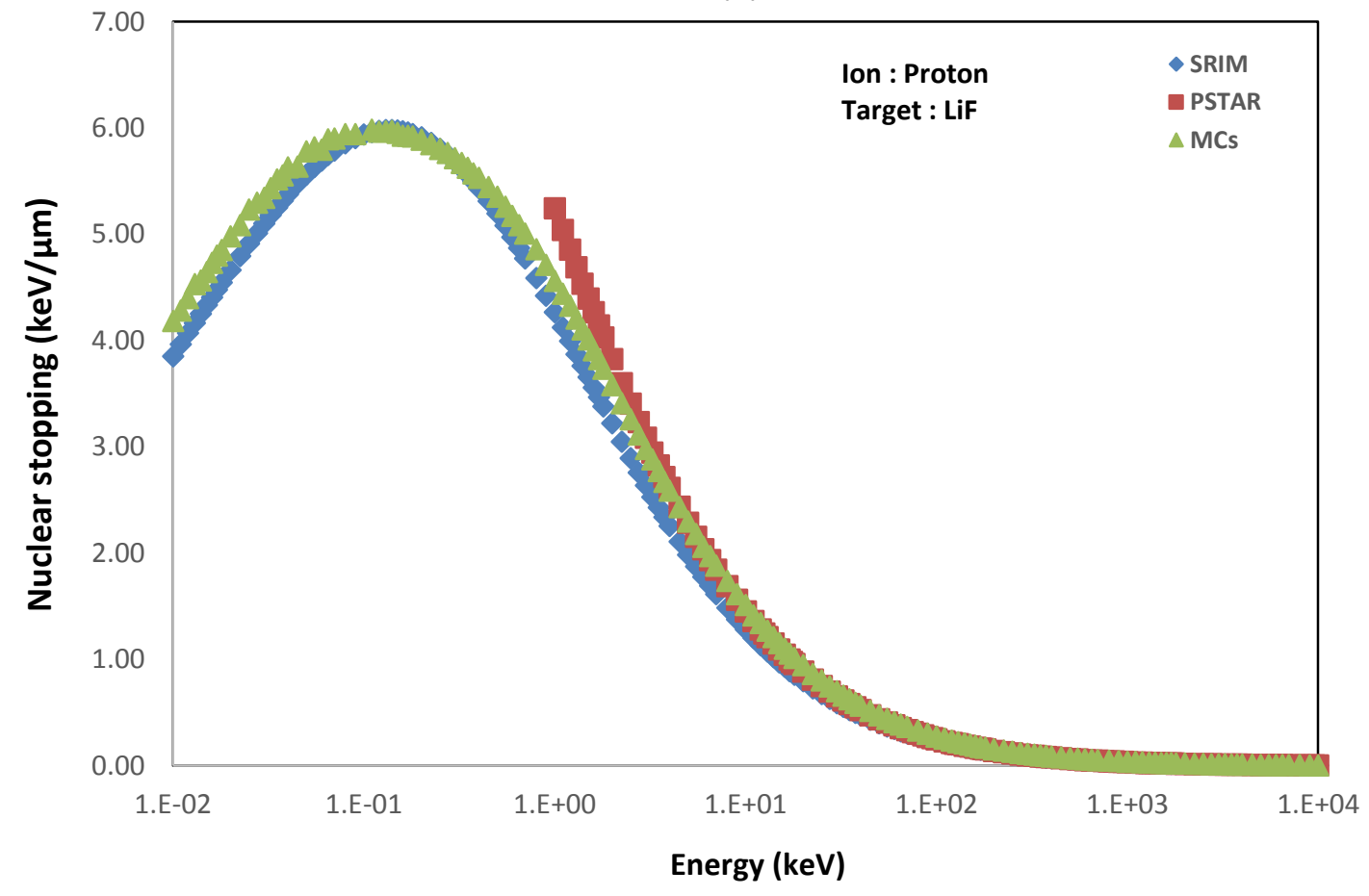




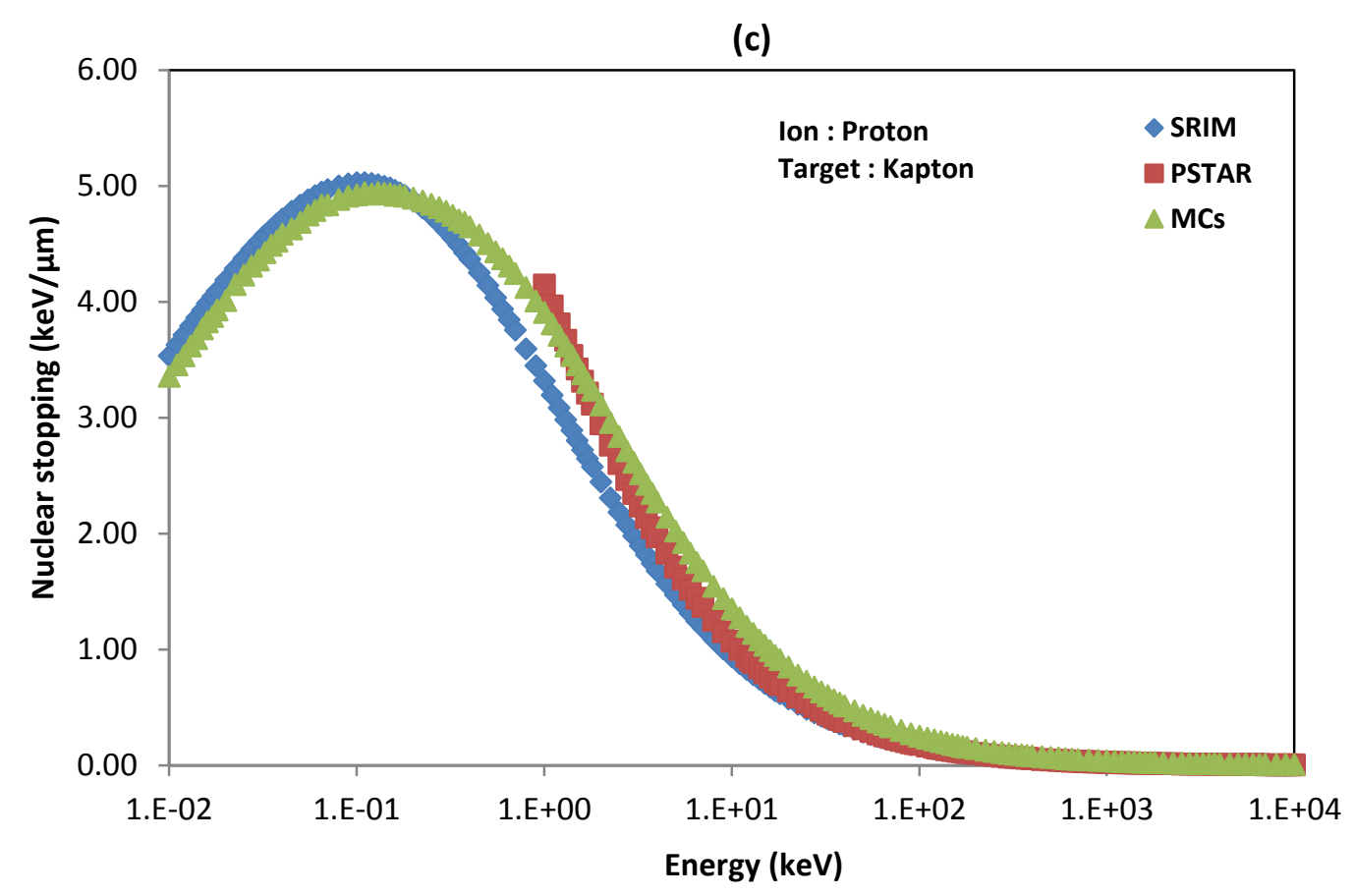

Figure 3. Nuclear stopping power behaviour in the energy range of interest for protons particles in $\mathrm{SiO}_{2}$ (a), $\mathrm{LiF}$ (b) and Kapton (c)

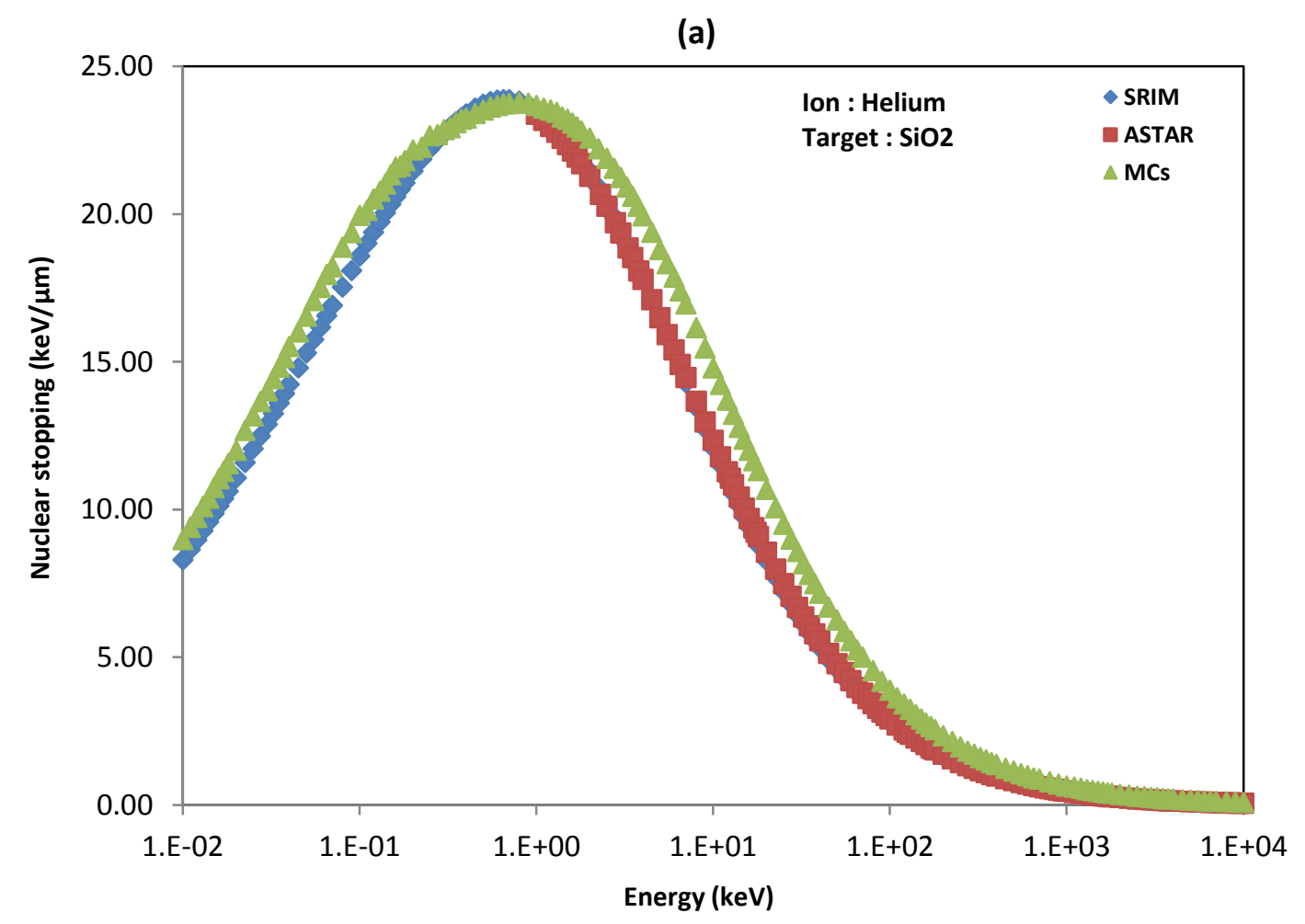


(b)

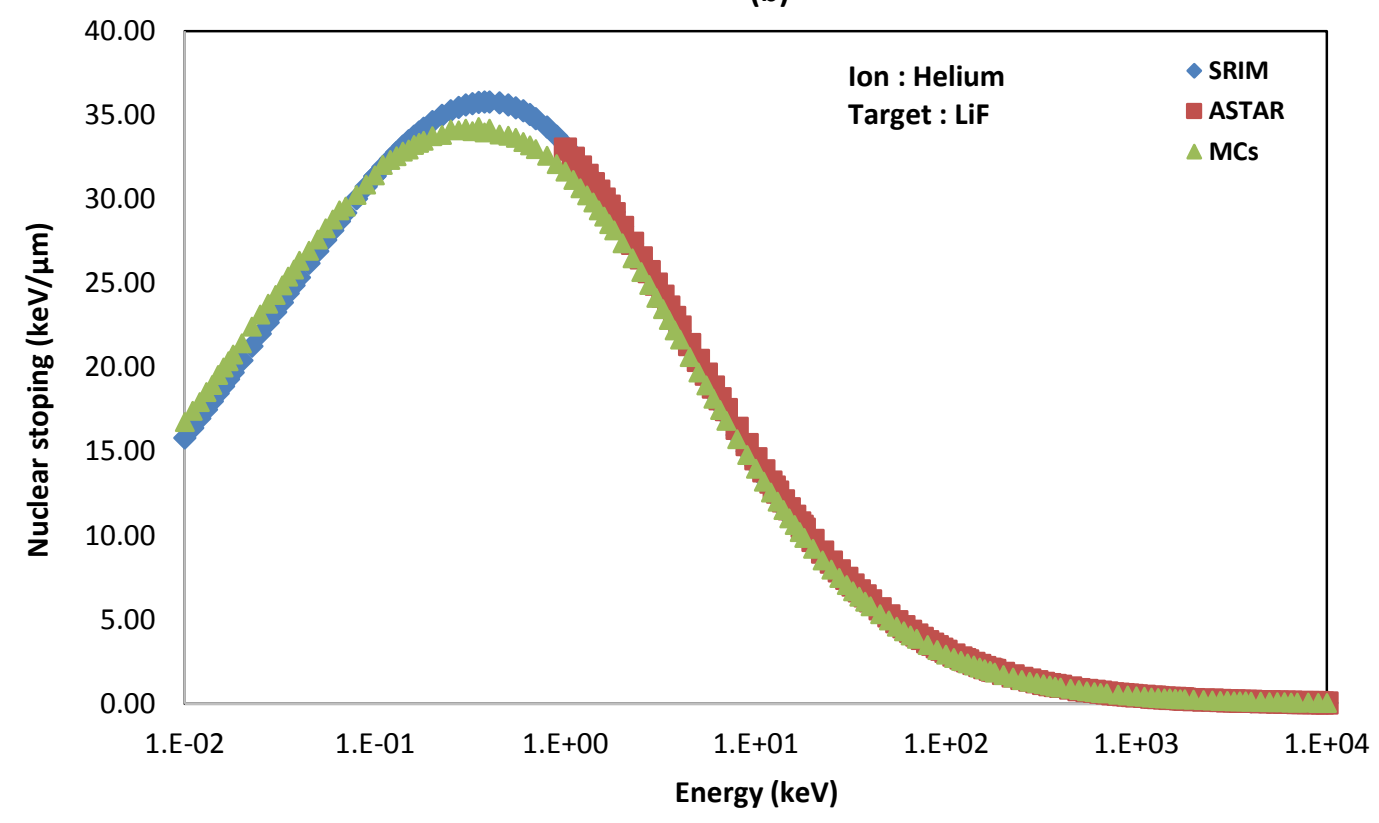

(c)

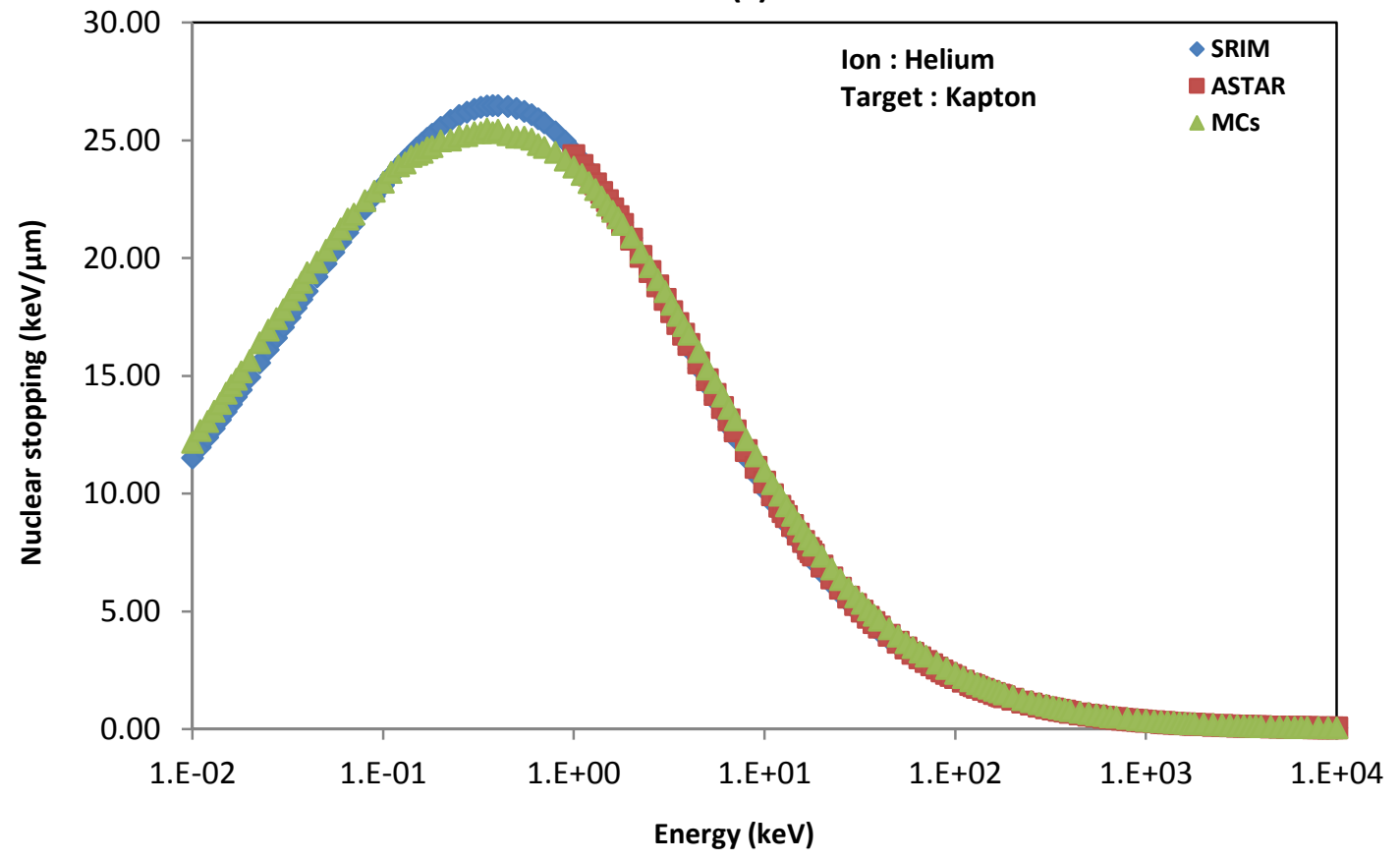

Figure 4. Nuclear stopping power behaviour in the energy range of interest for helium particles in $\mathrm{SiO}_{2}$ (a), $\mathrm{LiF}$ (b) and Kapton (c)

Figures. 5, 6 and 7 shows the behaviour of nuclear energy loss versus of kinetic energy for ${ }^{11} \mathrm{~B},{ }^{14} \mathrm{~N}$ and ${ }^{58} \mathrm{Ni}$ in $\mathrm{SiO}_{2}, \mathrm{LiF}$ and Kapton. All curves of the nuclear stopping increase when increasing the incident energy until a maximum, and then decreases as the energy of the ion increases. The curve of nuclear energy loss has a maximum at $113.36 \mathrm{keV} / \mu \mathrm{m}$ for ${ }^{11} \mathrm{~B}$, $177.1 \mathrm{keV} / \mu \mathrm{m}$ for ${ }^{14} \mathrm{~N}$ and $1087.7 \mathrm{keV} / \mu \mathrm{m}$ for ${ }^{58} \mathrm{Ni}$ in target
$\mathrm{SiO}_{2}$, see figures. 5(a), (b) and (c), respectively. In addition, the figures. 6(a), (b) and (c), shows the maximum of nuclear energy loss in target $\mathrm{LiF}$ at $150.5 \mathrm{keV} / \mu \mathrm{m}, 236.2 \mathrm{keV} / \mu \mathrm{m}$ and $1303.2 \mathrm{keV} / \mu \mathrm{m}$ for $11 \mathrm{~B}, 14 \mathrm{~N}$ and $58 \mathrm{Ni}$, respectively. For target kapton, the curve of nuclear energy loss has a maximum at $105.8 \mathrm{keV} / \mu \mathrm{m}$ for ${ }^{11} \mathrm{~B}, 158.1 \mathrm{keV} / \mu \mathrm{m}$ for ${ }^{14} \mathrm{~N}$ and 828.2 $\mathrm{keV} / \mu \mathrm{m}$ for ${ }^{58} \mathrm{Ni}$, see figures. $7(\mathrm{a})$, (b) and (c), respectively. 
International Journal of Engineering Research and Technology. ISSN 0974-3154, Volume 13, Number 9 (2020), pp. 2275-2287

(C) International Research Publication House. https://dx.doi.org/10.37624/IJERT/13.9.2020.2275-2287

However, it is shown that when increasing the atomic number of each incident particle, the nuclear energy loss increases, whereas, this nuclear stopping increase with increasing the incident energy in different amorphous targets until maximum values. These results showed that the contribution, of atomic number of incident heavy ions is important on a nuclear energy loss. This is probably due to the fact that when the number of incident particles is increased, the number of interactions increases, which leads to an increase in the energy lost.

Indeed, the majority of low-energy incident particle deposit their energy in a short distance inside of the target materials. On the other hand, the results obtained by our method of calculation are in good agreement, compared with those obtained by using SRIM code theoretical predictions [24].

(a)

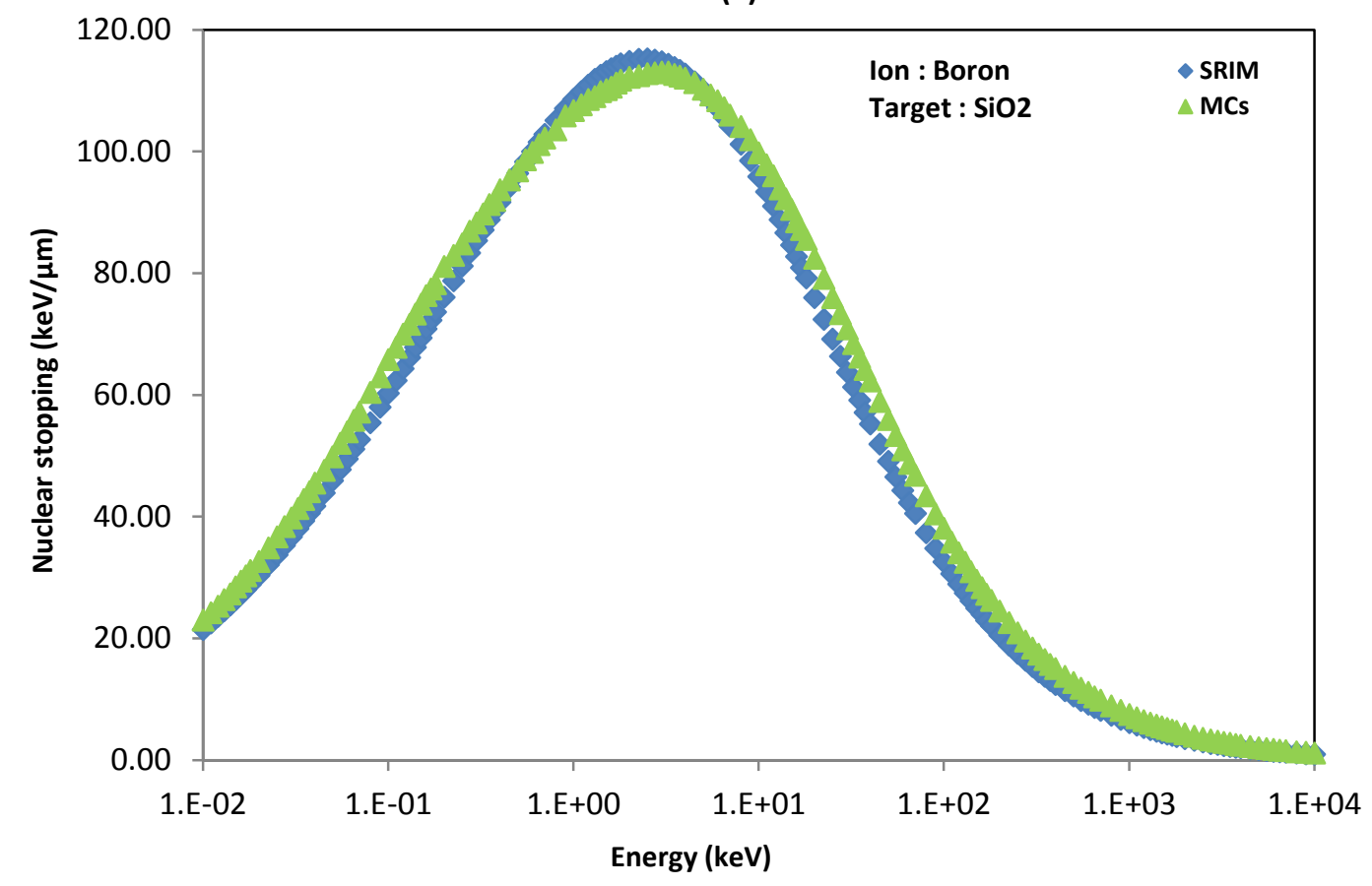

(b)

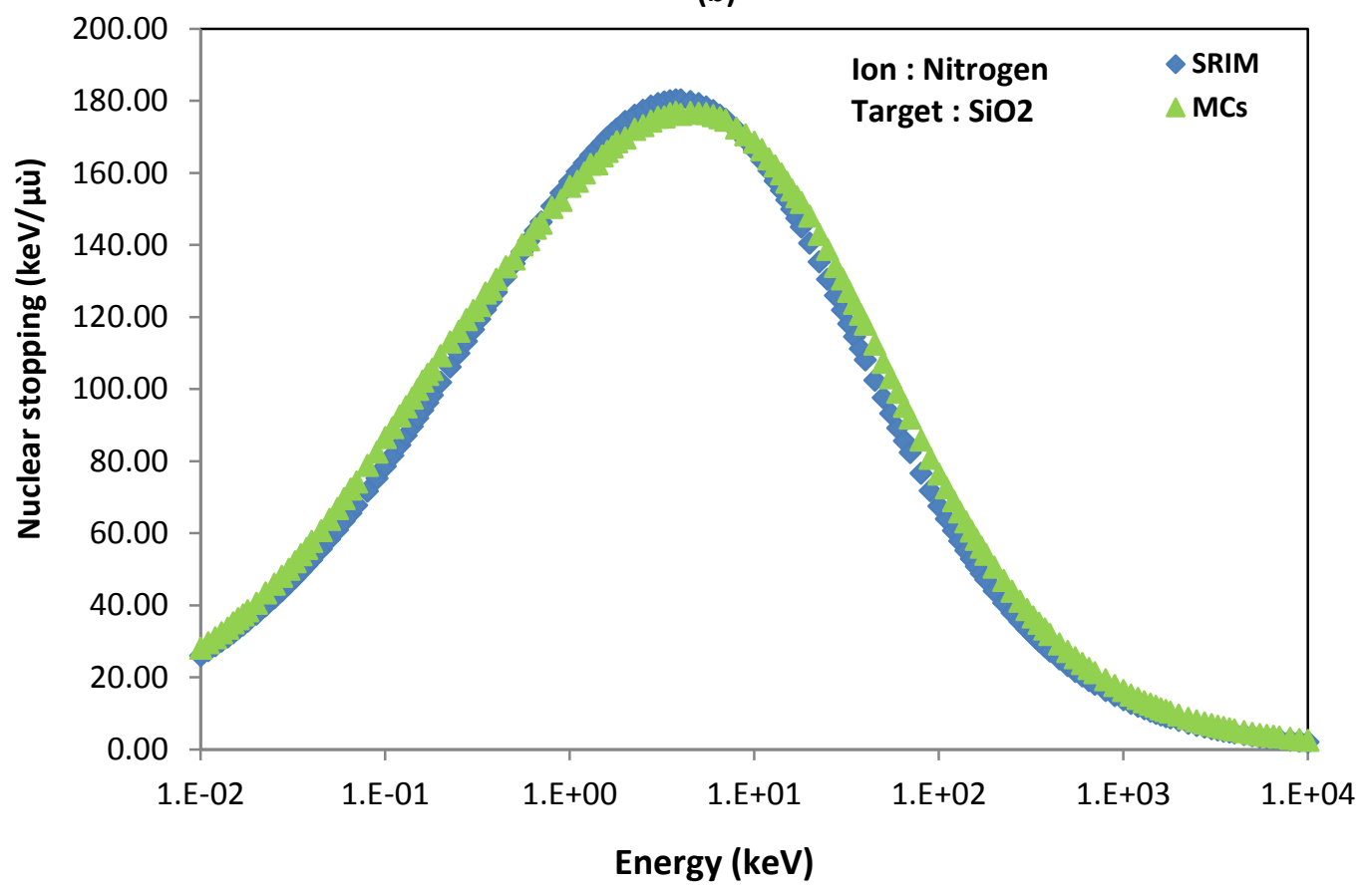


(c)

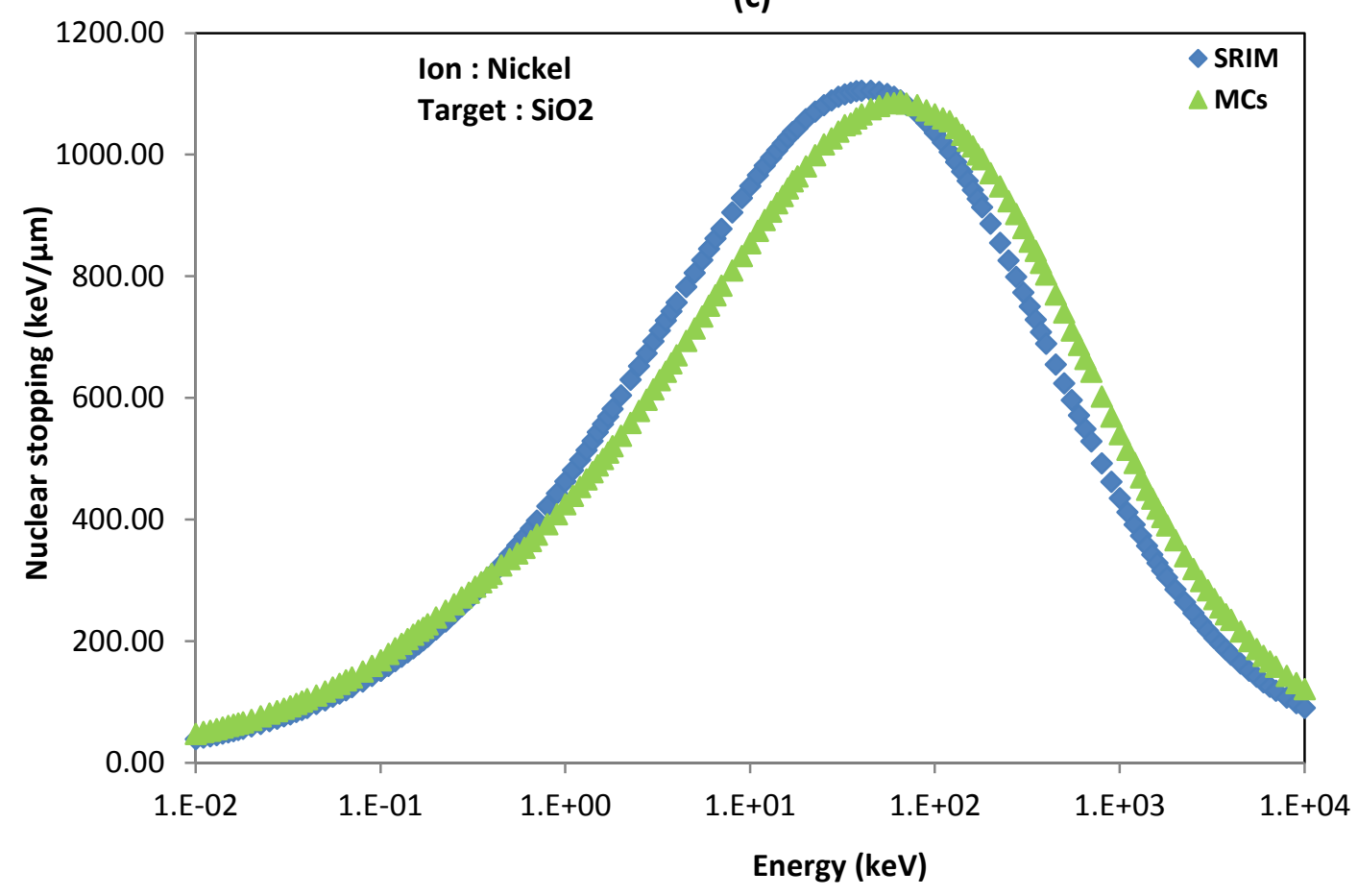

Figure 5 : Nuclear stopping power behaviour in the energy range of interest for ${ }^{11} \mathrm{~B}(\mathrm{a}),{ }^{14} \mathrm{~N}(\mathrm{~b})$ and ${ }^{58} \mathrm{Ni}$ (c) particles in $\mathrm{SiO}_{2}$

(a)

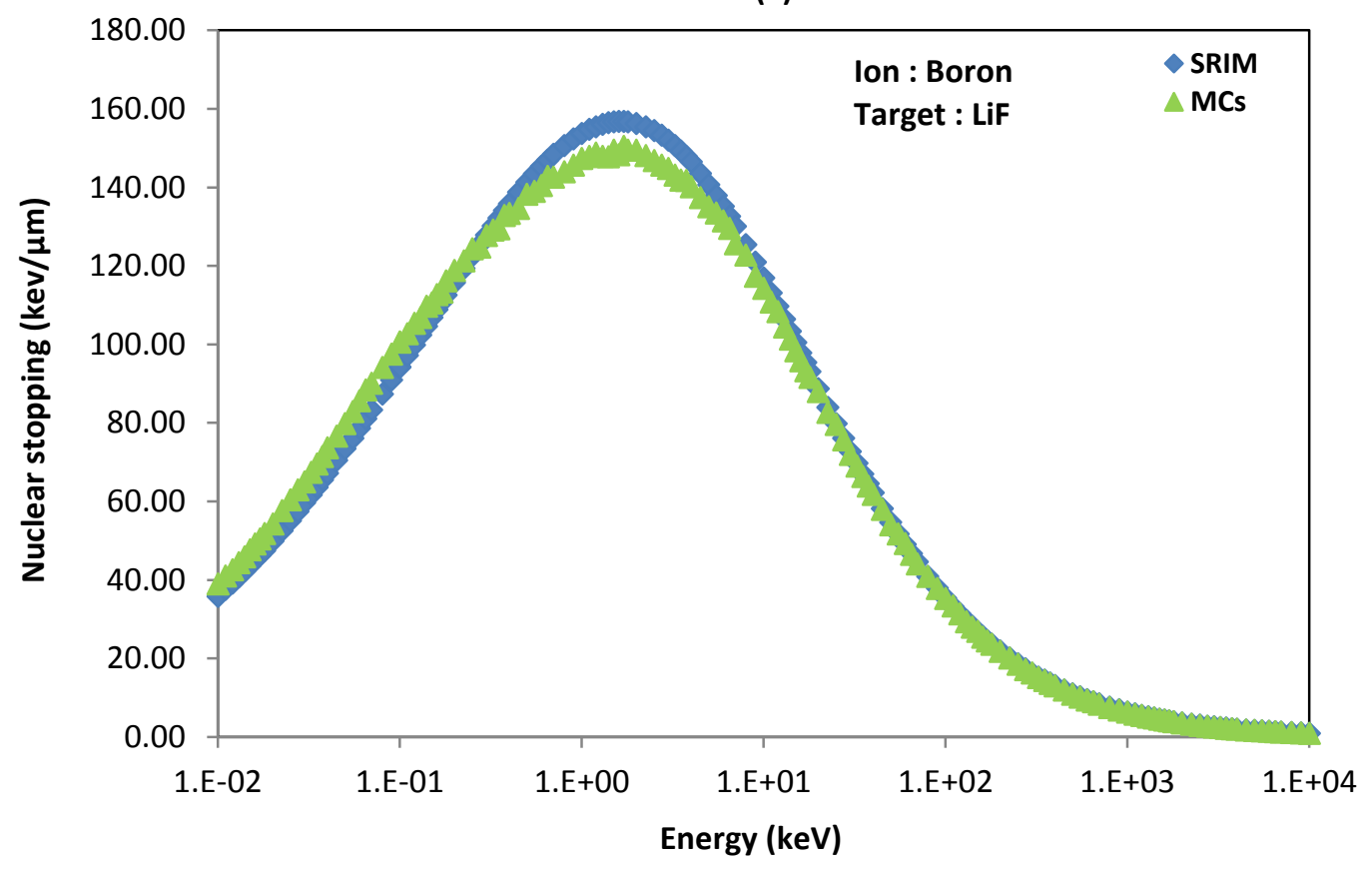


(b)

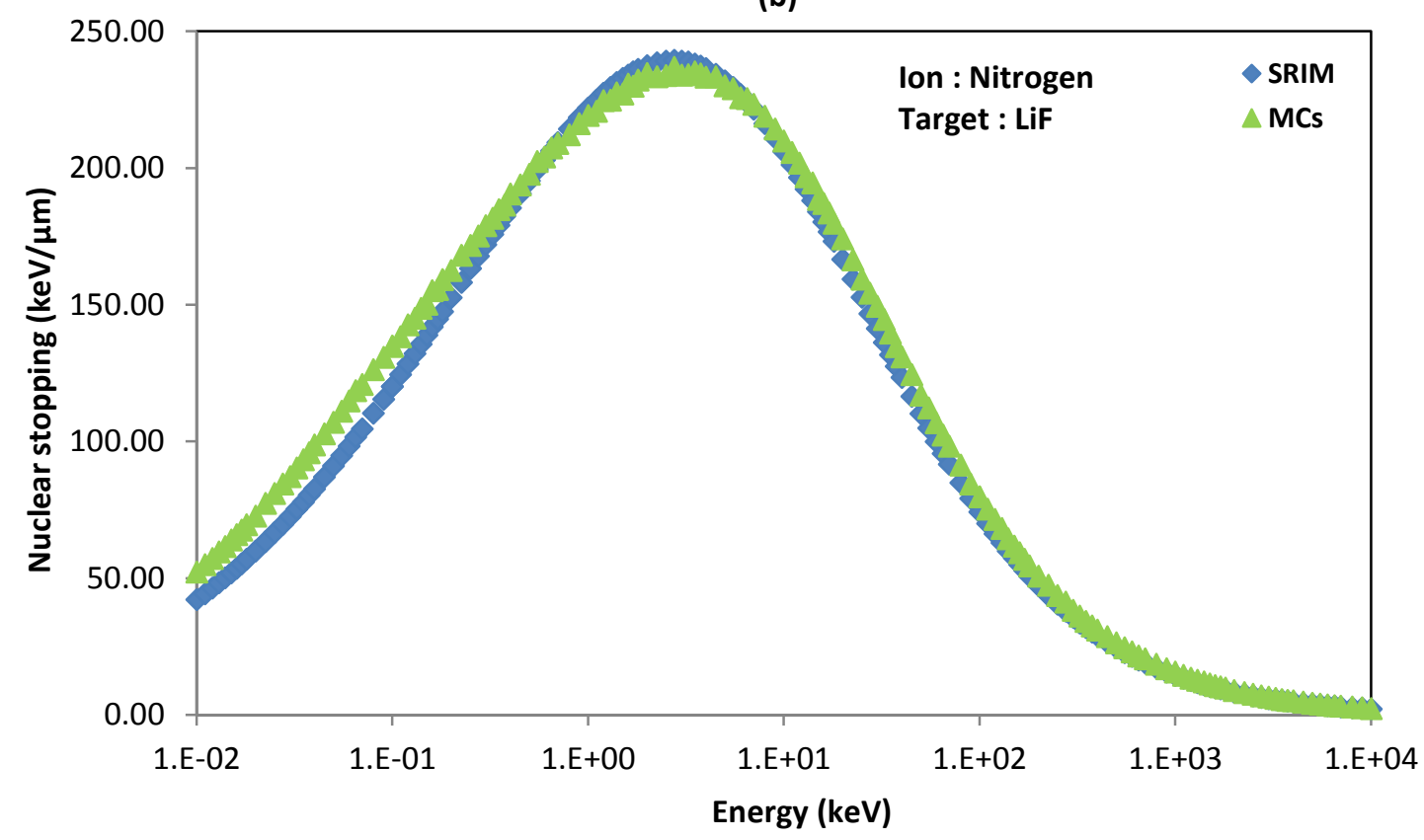

(c)

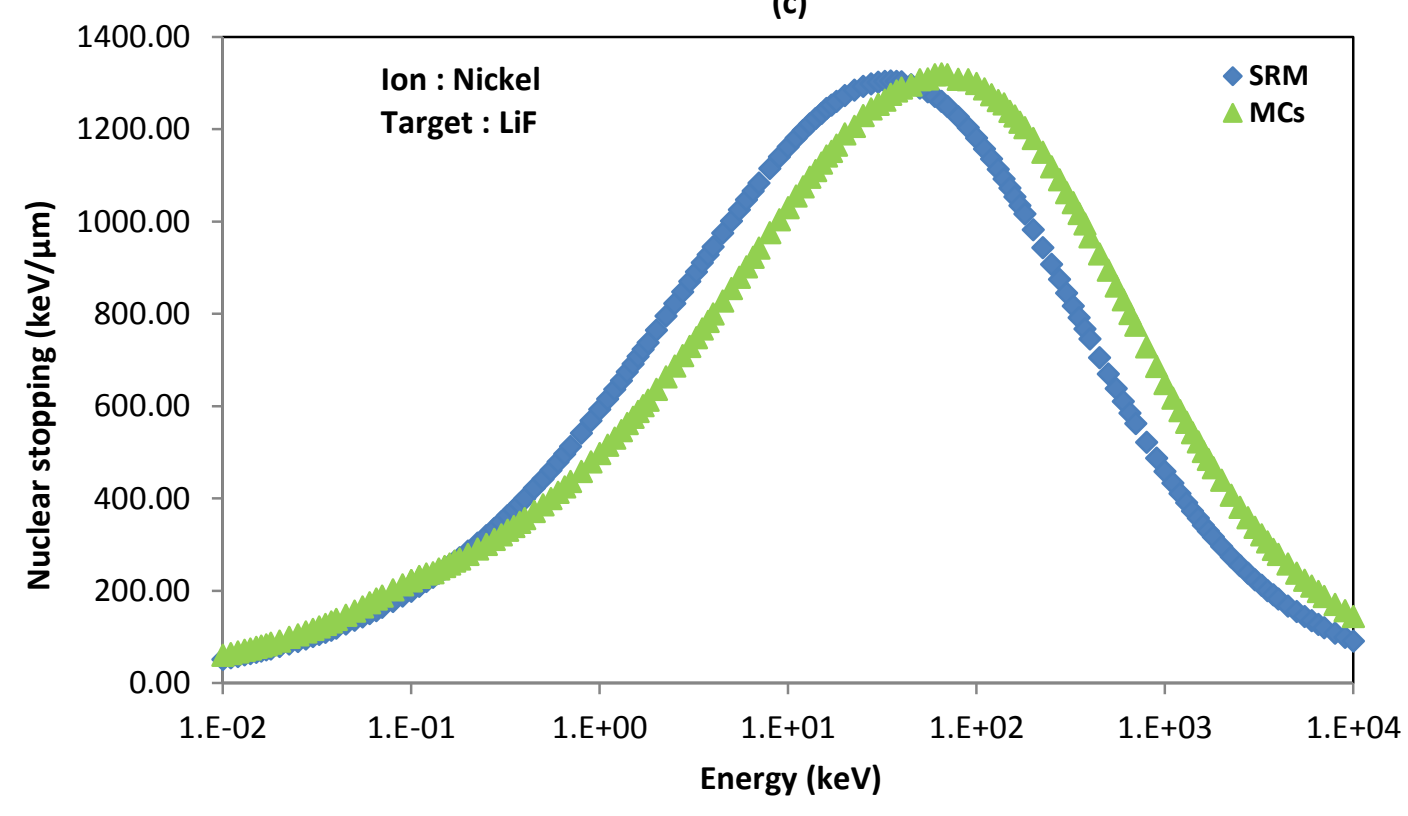

Figure 6 : Nuclear stopping power behaviour in the energy range of interest for ${ }^{11} \mathrm{~B}(\mathrm{a}),{ }^{14} \mathrm{~N}$ (b) and ${ }^{58} \mathrm{Ni}$ (c) particles in $\mathrm{LiF}$ 
(a)

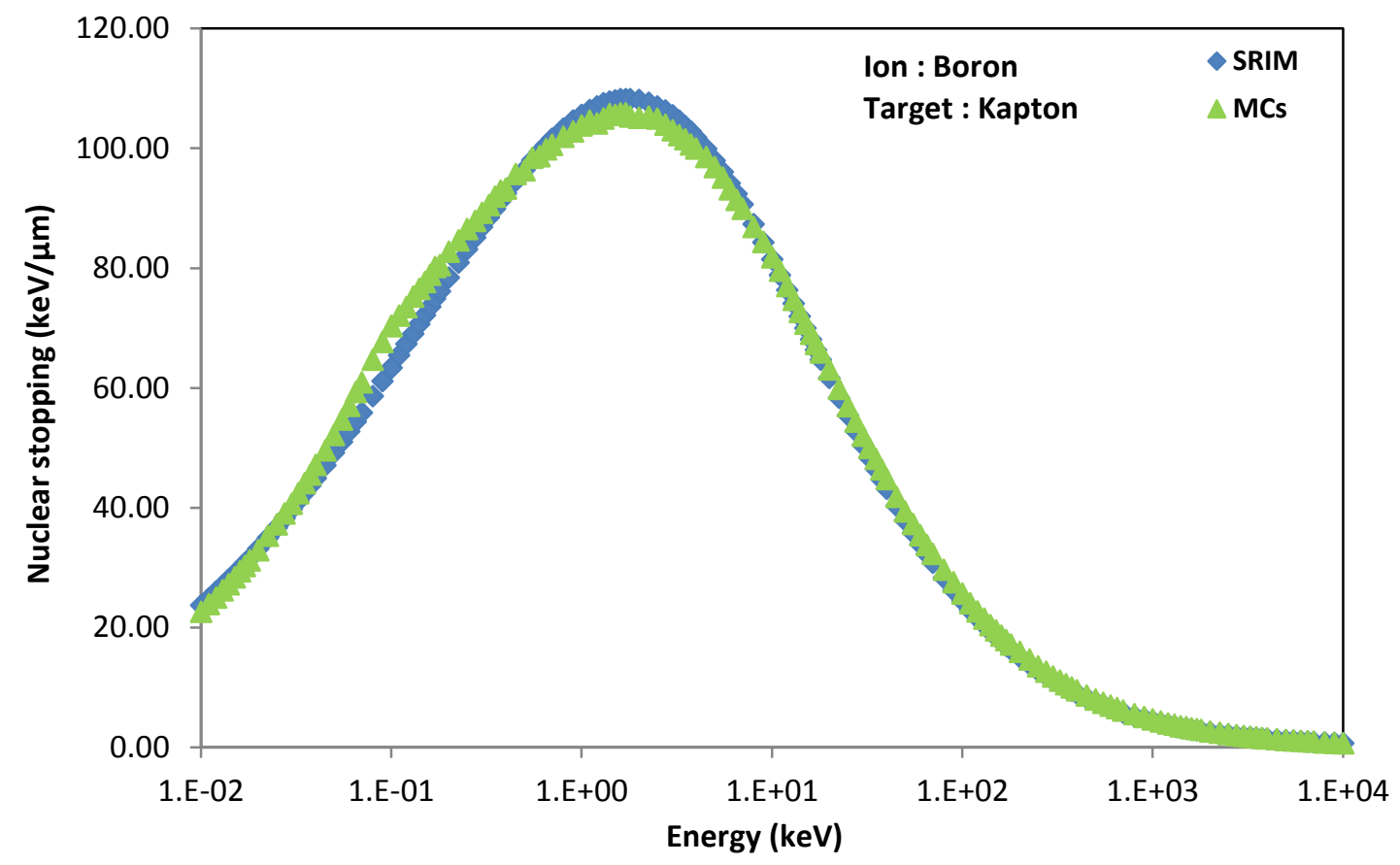

(b)

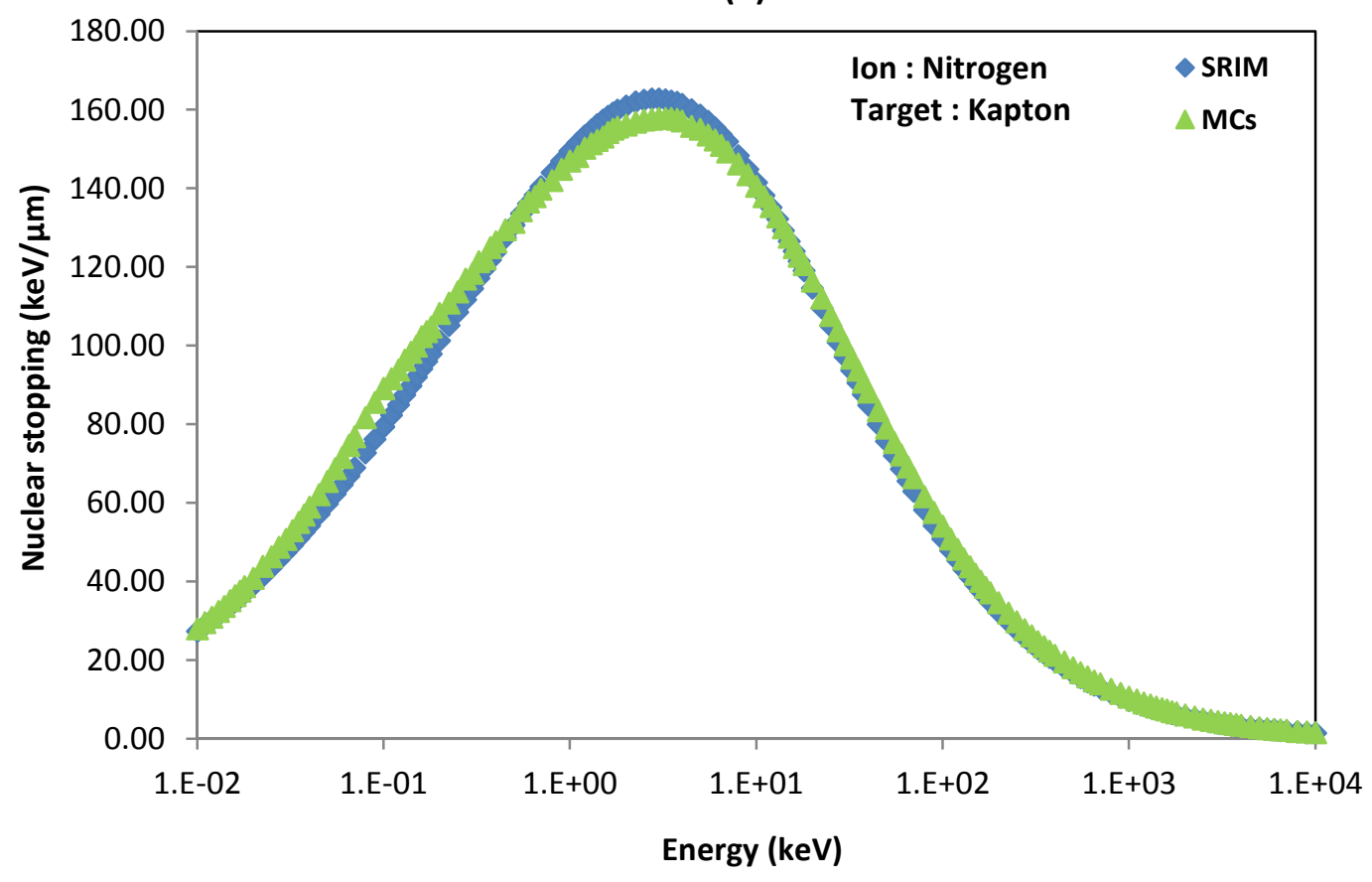


(c)

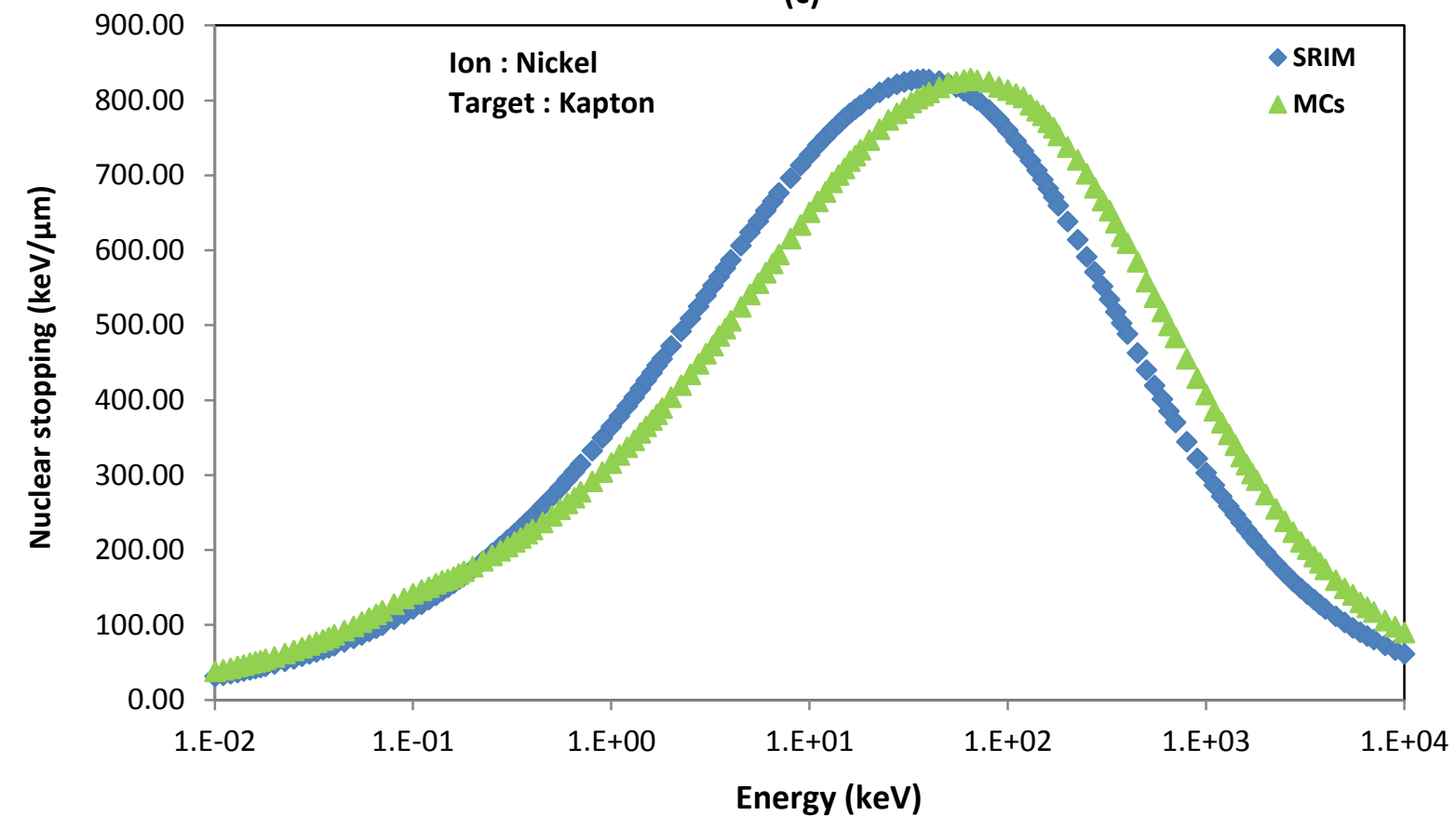

Figure 7 : Nuclear stopping power behaviour in the energy range of interest for ${ }^{11} \mathrm{~B}(\mathrm{a}),{ }^{14} \mathrm{~N}(\mathrm{~b})$ and ${ }^{58} \mathrm{Ni}(\mathrm{c})$ particles in Kapton

Using the Monte Carlo method, the mean range was also determined for $\mathrm{Au}, \mathrm{Bi}, \mathrm{Br}$ and $\mathrm{Hg}$ heavy ions in $\mathrm{SiO} 2$ amorphous targets in the energy interval from 10 to $400 \mathrm{keV}$.

Table 2. Comparison of experimental and calculated range for ions $\mathrm{Au}$ and $\mathrm{Bi}$ in $\mathrm{SiO}_{2}$.

\begin{tabular}{|c|c|c|c|c|c|c|c|c|}
\hline \multirow[b]{3}{*}{ Energy (keV) } & \multicolumn{8}{|c|}{ Range $(\AA)$} \\
\hline & \multicolumn{4}{|c|}{$\mathbf{A u}$} & \multicolumn{4}{|c|}{$\mathbf{B i}$} \\
\hline & Exp. [27] & SRIM & $\begin{array}{l}\text { Other calc. } \\
\qquad[28]\end{array}$ & Present work & Exp. [27] & SRIM & $\begin{array}{c}\text { Other calc. } \\
{[28]}\end{array}$ & $\begin{array}{c}\text { Present } \\
\text { work }\end{array}$ \\
\hline 10 & --- & 116 & & 120 & 94 & 118 & 135 & 112 \\
\hline 15 & 135 & 143 & 162 & 141 & 112 & 144 & 166 & 123 \\
\hline 20 & 142 & 166 & 187 & 152 & 140 & 167 & 191 & 155 \\
\hline 30 & 200 & 207 & 234 & 205 & 185 & 207 & 238 & 192 \\
\hline 50 & 315 & 278 & 313 & 317 & 260 & 277 & 316 & 271 \\
\hline 70 & 365 & 341 & 382 & 374 & 345 & 339 & 386 & 351 \\
\hline 100 & 469 & 428 & 481 & 473 & 395 & 425 & 483 & 403 \\
\hline 150 & --- & 562 & --- & 581 & --- & 555 & --- & 578 \\
\hline 200 & 700 & 688 & 773 & 708 & 655 & 677 & 770 & 667 \\
\hline 250 & --- & 810 & --- & 837 & & 794 & --- & 826 \\
\hline 300 & --- & 928 & --- & 958 & & 908 & --- & 931 \\
\hline 350 & --- & 1044 & --- & 1081 & & 1020 & --- & 1038 \\
\hline 400 & 1230 & 1159 & 1310 & 1243 & 1150 & 1129 & 1290 & 1163 \\
\hline
\end{tabular}


In addition, we are calculated the values of mean range of some heavy ions such as $\mathrm{Au}, \mathrm{Bi}, \mathrm{Br}$ and $\mathrm{Hg}$ in $\mathrm{SiO} 2$. To validate our results, the obtained values by our calculations program and those obtained experimentally and theoretically by other authors [27-30] are presented in table 2 and 3. Comparison with the previously works is performed and the result are found to be in close agreement.
In the light of these results, we notice that the mean range of ions, in amorphous targets increases with the increasing the kinetic energy, whereas, at fixed kinetic energy value the mean range decreases with the increasing of atomic number. Our results, obtained by Monte Carlo simulations, were found to be in close agreement with experiment results [27, 29].

Table 3. Comparison of experimental and calculated range for ions $\mathrm{Br}$ and $\mathrm{Hg}$ in $\mathrm{SiO}_{2}$.

\begin{tabular}{|c|c|c|c|c|c|c|c|c|}
\hline \multirow[b]{3}{*}{$\begin{array}{c}\text { Energy } \\
(\mathrm{keV})\end{array}$} & \multicolumn{8}{|c|}{ Range (̊̊) } \\
\hline & \multicolumn{4}{|c|}{$\mathbf{B r}$} & \multicolumn{4}{|c|}{$\mathrm{Hg}$} \\
\hline & Exp. [29] & SRIM & $\begin{array}{c}\text { Other calc. } \\
{[28]}\end{array}$ & Present work & Exp. [30] & SRIM & $\begin{array}{c}\text { Other calc. } \\
{[28]}\end{array}$ & $\begin{array}{c}\text { Present } \\
\text { work }\end{array}$ \\
\hline 10 & $\overline{---}$ & 115 & --- & 140 & $\overline{---}$ & 117 & --- & 143 \\
\hline 15 & --- & 149 & --- & 161 & --- & 144 & --- & 165 \\
\hline 20 & --- & 181 & --- & 192 & --- & 167 & --- & 180 \\
\hline 30 & --- & 242 & --- & 266 & --- & 208 & --- & 266 \\
\hline 50 & 411 & 356 & 352 & 423 & 368 & 279 & 323 & 375 \\
\hline 70 & --- & 468 & --- & 518 & --- & 342 & --- & 395 \\
\hline 100 & 668 & 635 & 627 & 690 & 497 & 429 & 482 & 506 \\
\hline 150 & 1028 & 916 & 900 & 1045 & 583 & 562 & 636 & 595 \\
\hline 200 & 1233 & 1202 & 1175 & 1249 & 754 & 687 & 773 & 766 \\
\hline 250 & 1542 & 1493 & 1451 & 1550 & 883 & 808 & 914 & 892 \\
\hline 300 & 1696 & 1791 & 1729 & 1708 & 1012 & 925 & 1050 & 1025 \\
\hline 350 & 1902 & 2096 & 2008 & 1915 & 1184 & 1040 & 1178 & 1195 \\
\hline 400 & 2055 & 2407 & 2286 & 2073 & 1269 & 1154 & 1300 & 1278 \\
\hline
\end{tabular}

\section{CONCLUSION}

In order to study the nuclear stopping power, we carried out by the calculations using the Monte Carlo method on the $\mathrm{SiO}_{2}, \mathrm{LiF}$ and Kapton materials. However, in the range of our energies and materials, our results are in excellent agreement with those found the SRIM code, the PSTAR and ASTAR. (a very small discrepancies, less than 5\%).

The corresponding behaviour of the nuclear stopping of the amorphous targets increases when increasing the incident kinetic energy until a maximum value and then decreases. The maximum of nuclear energy loss increases with increasing the atomic number of incident particle. The contribution of the nuclear stopping power to the total stopping cross section is dominant only at low energy. However, its significance in the theory of radiation effects, such as radiation damage and the relation between mean range and total range, makes the study of nuclear collisions important. The heavy ion mean ranges in amorphous target $\mathrm{SiO}_{2}$, have been also calculated by using a Monte Carlo simulation based on the transport theory. $\mathrm{Au}, \mathrm{Br}$, $\mathrm{Bi}$ and $\mathrm{Hg}$ projectiles have been chosen as incident ion. Furthermore, it is found that the agreement between calculated values on mean range and the experiment is good (less than 5 $\%)$.

\section{REFERENCES}

[1] N. Bohr, Mat. Fys. Medd. Dan. Vid. Selsk. 18 (8) (1948) 1.

[2] J. Lindhard, M. Scharff, H.E. Schiøtt, Mat. Fys. Medd. Dan. Vid. Selsk. 33 (14) (1963) 1.

[3] J.F. Ziegler, Biersack, U. Littmark, The Stopping and Range of Ions in Solids, vol. 1. Pergamon, New York (1985).

[4] P. Sigmund, Stopping of Heavy Ions: A Theoretical Approach, Springer tracts in modern physics. Springer, 204 (2004).

[5] H. Erramli, O. El Bounagui, M.A. Misdaq, A. Merzouki, A Monte Carlo computer code for evaluating energy loss of $10 \mathrm{keV}$ to $10 \mathrm{MeV}$ ions in amorphous silicon materials, Nucl. Instr. Meth. B 263 (2007) 127-131.

[6] M. T. Robinson, The binary collision approximation: Background and introduction, Rad. Eff. Def. in Sol, 130 (1994) 3-20.

[7] O. El Bounagui, H. Erramli, Channeling energy loss in silicon by using numerical and experimental methods, Modern Physics Letters B25 (2011) 2171-2181. 
[8] K. Parodi, S. Squarcia, "Improvement of low-energy stopping power algorithms in the FLUKA simulation program,' Nucl. Instr. Meth A 456 (2001) 352-368

[9] O. Geithner, P. Andreo, N. Sobolevsky, G. Hartmann,O. Jokel, Physics in Medicine and Biology 51 (2006) 2279.

[10] J.F. Ziegler, Nucl. Instr. Meth. B 219-220 (2004) 1027.

[11] H. Paul, https://www-nds.iaea.org/stopping/MSTAR V.3.12 <https://www-nds.iaea.org/stopping/>.

[12] J. P. Biersack and L. G. Haggmark, A Monte Carlo computer program for the transport of energetic ions in amorphous targets, Nucl. Instr. Meth. 174 (1980) 257.

[13] J. El Asri, O. El Bounagui, N. Tahiri, H. Erramli, A. Chetaine, "Electronic Stopping Powers of Formvar and Mylar Polymeric Materials for Heavy Ions: LSS Modified Theory and Monte Carlo Simulation, "Nuclear Technology, 205 (2019) 1236-1244.

[14] E. Balanzat, S. Bouffard, Materials under Irradiation, Trans Tech. Publication (1993).

[15] T. Ishitani, R. Shimizu, K. Murata, Monte Carlo Simulations on Scattering of Bombarded Ions in Solids, Japanese. J. App. Phys, 11 (1972) 125-133.

[16] M. T. Robinson, I. M. Torrens, Computer simulation of atomic-displacement cascades in solids in the binarycollision approximation, Phys. Rev. B 9 (1974) 5008.

[17] A. A. Pasternak et al, The stopping power of heavy ions for energies below $0.2 \mathrm{MeV} /$ nucleon measured by the semi-thick target method, Nucl. Instr. and Meth. A 774 (2015) 82-88.

[18] Pawanpreet Kaur, K. K. Sharma, Rabia Pandit, Ravi Kumar, Journal of Magnetism and Magnetic Materials (2015) 398

[19] J. Lindhard and M. Scharff. Energy dissipation by ions in the keV région. Phys Rev., 124-1 (1961) 128.

[20] G. Moliere, Z. Naturforsch. A 2 (1947) 133.

[21] J. Lindhard, V. Nielsen, M. Scharff, P.V. Thomsen, Integral equation governing radiation effects. (Notes on atomic collisions, III), Kgl. Danske Videnskab., Selskab. Mat. Fys. Medd. 33 (1963).

[22] J. von NEUMANN, "Various Techniques Used in Connection with Random Digits," J. Res. Nat. Bur. Stand. Appl. Math. Series, 12 (1951) 36.

[23] J. P. NOUGIER, Méthode de calculs numérique, p. 325, $3^{\text {rd }}$ ed., Elsevier Masson, Paris (1991).

[24] F. Ziegler, SRIM 2008.04, 〈http://www.srim.org>.

[25] ICRU (1993). International Commission on Radiation Units and Measurements. Stopping Power and Ranges for Protons and Alpha Particles, ICRU Report 49 (International Commission on Radiation Units and Measurements, Bethesda, MD).

[26] ICRU (2014). International Commission on Radiation Units and Measurements. ICRU Report 90, Key Data for
Ionizing-Radiation Dosimetry: Measurement Standards and Applications. ICRU Report 90, J. ICRU 14 (Oxford University Press, Oxford)

[27] P. L. Grande, P.F.P Fichtner, M. Behar, R.P. Livi, F.C. Zawislak, J.P. Biersack, D. Fink and P. Mertens, Nucl. Instrum. Meth. B. 19/20 (1987) 25.

[28] Wang Ke-Ming and Shi Bo-Rong, J. Phys. D: Appl. Phys. 23 (1990) 1282-1289.

[29] Wang Ke-Ming, Wang Yi-Hua and Liu Ji-Tian, Sci. Sinica A 6 (1987) 597.

[30] Wang Ke-Ming, Liu Xi-Ju, Wang Yi-Hua, Liu Ji-Tian, Guo Hai-Yan and Shi Bo-Rong, Phys. Lett. A 125 (1987) 366. 